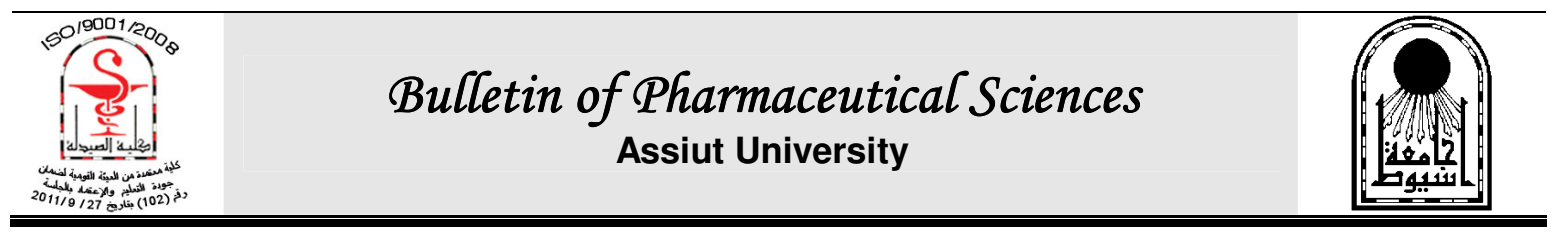

\title{
ANTIBIOTIC DISPENSING WITHOUT PRESCRIPTION IN JORDANIAN COMMUNITY PHARMACIES: A PHARMACIST'S PERSPECTIVE
}

\author{
Amjad Abuirmeileh $^{1}$, Sondos Samara ${ }^{1}$, Alaa Alkhodari ${ }^{1}$, Anas Bahnassi ${ }^{2}$, Ahmad Talhouni ${ }^{1}$ \\ and Alaa M. Hayallah ${ }^{3 *}$ \\ ${ }^{1}$ Department of Clinical Pharmacy \& Applied Pharmaceutical Sciences, Faculty of Pharmacy, \\ Al Isra University, 11622 Amman, Jordan \\ ${ }^{2}$ Clinical and Hospital Pharmacy, Faculty of Pharmacy - Taibah University, Al Madinah Al \\ Munawwarah, Saudi Arabia \\ ${ }^{3}$ Pharmaceutical Organic Chemistry Department, Faculty of Pharmacy, Assiut University, \\ 71526, Egypt
}

\begin{abstract}
The sale of antibiotics without medical prescriptions has been recognized as a major source of drug misuse and medication risk in Jordan. This practice constitutes one of the major causes of the on going problem of antibiotic resistance. This study provides a pharmacist perspective on the problem through presenting the most common antibiotics dispensed, the related indications, and pharmacists proposed solutions to this problem in the city of Amman, Jordan. This was achieved by means of a structured questionnaire prepared by the investigators and completed by the pharmacists themselves. It was suggested that the problem at hand can be overcome through the enforcement of laws to control such practice. Also, increasing awareness among patients and pharmacists, and empowering pharmacists to play more active role in patients care are important steps that will contribute in minimizing this practice.
\end{abstract}

\section{INTRODUCTION}

Providing pharmaceutical care is one of the primary tasks a clinical pharmacist should provide to his patients. It is defined as a patient-centered, outcomes oriented pharmacy practice that requires the pharmacist to work in concert with the patient and the patient's other healthcare providers to promote health, to prevent disease, and to assess, monitor, initiate, and modify medication use to assure that drug therapy regimens applied are safe and effective ${ }^{1}$.

Self-medication is defined as the selection and use of medicines by individuals to treat self-recognized illnesses or symptoms. These medications should be used to treat selfrecognized conditions, either chronic or recurrent, following initial diagnosis, and need to be designed for this purpose ${ }^{1}$.
The practice of self-medication can result in self-harm; especially when considering a class of medications like antibiotics (ABs), where their use requires professional diagnosis, dosing adjustments, and treatment follow up. Using such medications directly without proper prescription by a physician exposes patients to unnecessary risk and possible $\mathrm{AB}$ resistance. The misuse and abuse of ABs has unfortunately significantly contributed to the appearance of antibiotic resistant microorganisms. This has led to a greater frequency of therapeutic failure and unnecessarily more complicated treatment regimens ${ }^{2}$.

Broad-spectrum antibacterial agents, including: ciprofloxacin, levofloxacin, amoxicillin/clavulanate, and piperacillintazobactam were among the 25 therapeutic categories with the highest drug expenditures

Received in 22/3/2014\& Accepted in 28/4/2014 
from 1999 to 2001 according to the National Institute of Health Care Management, USA ${ }^{3}$.

Several studies have been conducted to evaluate the frequency of self-medication and $\mathrm{AB}$ dispensing without prescription among different populations. Where some studies mainly focused on the patients' perspective $e^{4-7}$, others reviewed the practice of healthcare providers in the hospital settings ${ }^{8}$ or in the community pharmacy setting ${ }^{9 \& 10}$.

Also, a study conducted in Jordan and Syria looked into the perception of healthcare providers regarding the problems and causes of the irrational use of drugs in this region in general, showed excessive use of antibiotics, and unwarranted use of antibiotics to treat minor upper respiratory tract infection ${ }^{11}$.

Self- medicated ABs is an issue in many countries especially among middle income people regardless of the variation of regulation, guidelines, culture or region. $60 \%$ of children patients in Yemen received $\mathrm{ABs}$ without prescription $^{12}$ and $56 \%$ of population in Abu Dhabi, UAE according to Abasaeed et. al. ${ }^{7}$.

In Jordan two studies showed a close estimation for dispensing $\mathrm{ABs}$ without prescription among the Jordanian population. Here, Yousef and co-workers estimated the percentage to be around $42.5 \%$ of the population $^{10}$ while Bakri and co-workers estimated the percentage around $46 \%$ of the population'.

The aim of this study was to investigate the common practice of dispensing ABs without prescription in community pharmacies in Amman, Jordan. More specifically this study was conducted in eastern Amman where these practices have long been observed. The study focused on the pharmacists' perspectives of this practice and their suggestions to control the dispensing of non-prescribed $\mathrm{ABs}$ in the Jordanian pharmaceutical market.

\section{MATERIALS AND METHODS}

A questionnaire was prepared and randomly distributed to 54 very well known pharmacies in eastern Amman. These questionnaires were answered by pharmacists practicing in these community pharmacies. The eastern Amman area was chosen because of the socioeconomic status of the population living in this area where medication prescription without prescription is a very common practice.

The questionnaire was tested by the researchers and five different practicing community pharmacists. No changes were required to be done.

Pharmacists had the choice to fill the questionnaire by their own or with the help of a researcher, especially where translation was required, as the questionnaire was written in English (appendix).

\section{Questionnaire structure}

The structure of the questionnaire was based on similar studies conducted in other countries. Grigoryan and co-workers studied the self-medication pattern among patients in south and eastern European countries with a low to middle income ${ }^{6}$. Here, Grigoryan and co-workers questionnaire was directed to test the patients' beliefs and attitudes toward the prescription of medicaments. Parts of their questionnaire $^{6}$ directed the questionnaire used in this study. Another study conducted in Greece by Skliros and co-workers studied AB self-medication ${ }^{4}$. From this study, the choice of $\mathrm{ABs}$ and their related indications were utilized in the questionnaire used in this study.

These two previous articles were chosen because of population similarities between these countries and Jordan according to World Bank economic classification.

Since that the questionnaire aimed to evaluate the pharmacists' perspective on $\mathrm{ABs}$ dispensing, the suggestive answers for questions 5 to 7 were deduced from discussions and excuses previously made by some pharmacists to the authors in a preliminary evaluation. These suggestive answers were also supported by the finding of Yousef and coworkers where they looked into self-patterns of medication use in Jordan. Among causes identified for self-medication were long waiting time at the doctor's clinic, costs of doctor visits, undermining the condition they have and thus the need for physical examination ${ }^{10}$. Since these causes of ABs dispensing where already identified by patients, a pharmacist perspective on the issue would be of much added value and would help demonstrate whether patients and pharmacists were in agreement on reasons for selfmedication in Jordan. 
The questions in part two of the questionnaire aimed to evaluate pharmacist's clinical practice when dispensing $\mathrm{ABs}$ without prescription, and whether they collected the most important information regarding patient's condition before dispensing $\mathrm{AB}$.

\section{RESULTS AND DISCUSSION}

\section{Results}

The questionnaire revealed that $(53.7 \%)$ of the interviewed pharmacists dispense $\mathrm{ABs}$ without prescription at a frequency of 1-5 times /day, (31.5\%) of them dispense ABs 5-10 times/day. Only 2 pharmacists out of the fifty four pharmacists interviewed reported not dispensing $\mathrm{ABs}$ without a prescription (Fig. 1).

When considering the types of $\mathrm{ABs}$ dispensed for pediatric patients, $83.5 \%$ of $\mathrm{ABs}$ dispensed by pharmacists contained amoxicillin or amoxicillin/Clavuanic acid. Azithromycin came second with $10.9 \%$. One pharmacist reported not dispensing $\mathrm{ABs}$ for pediatric patients. Yet, she acknowledged dispensing $\mathrm{ABs}$ to Adult patients without proper prescription (Fig. 2).

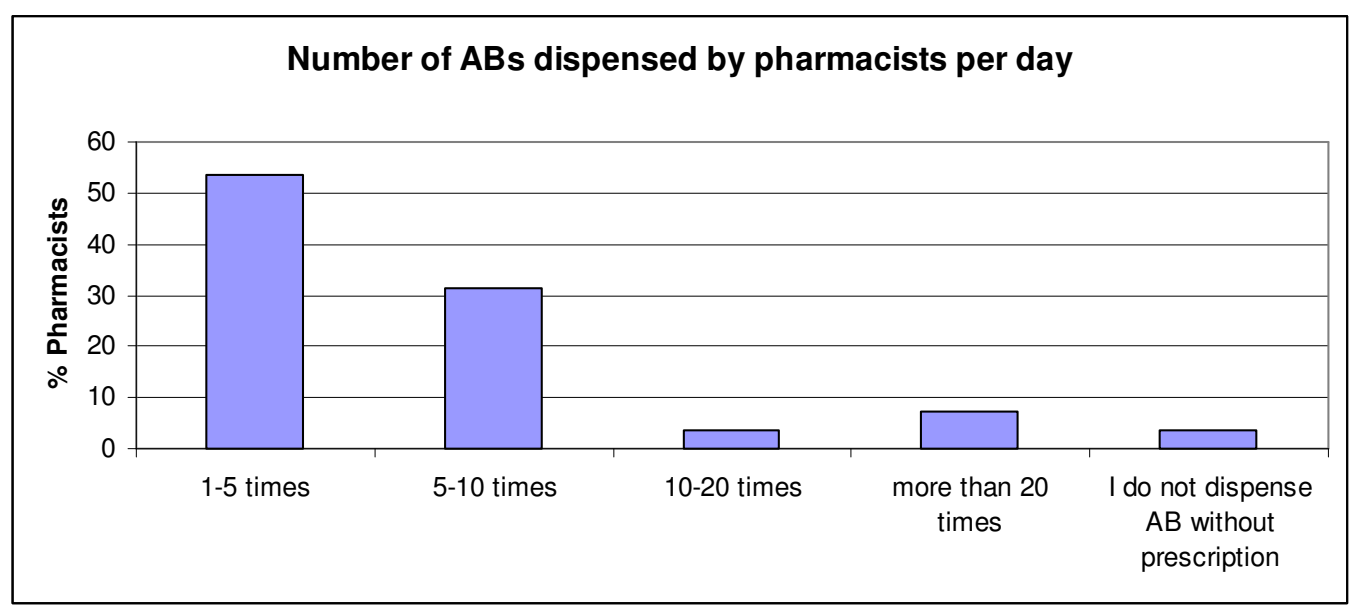

Fig. 1: Figure illustrates the number of ABs dispensed by pharmacists without prescription every day.

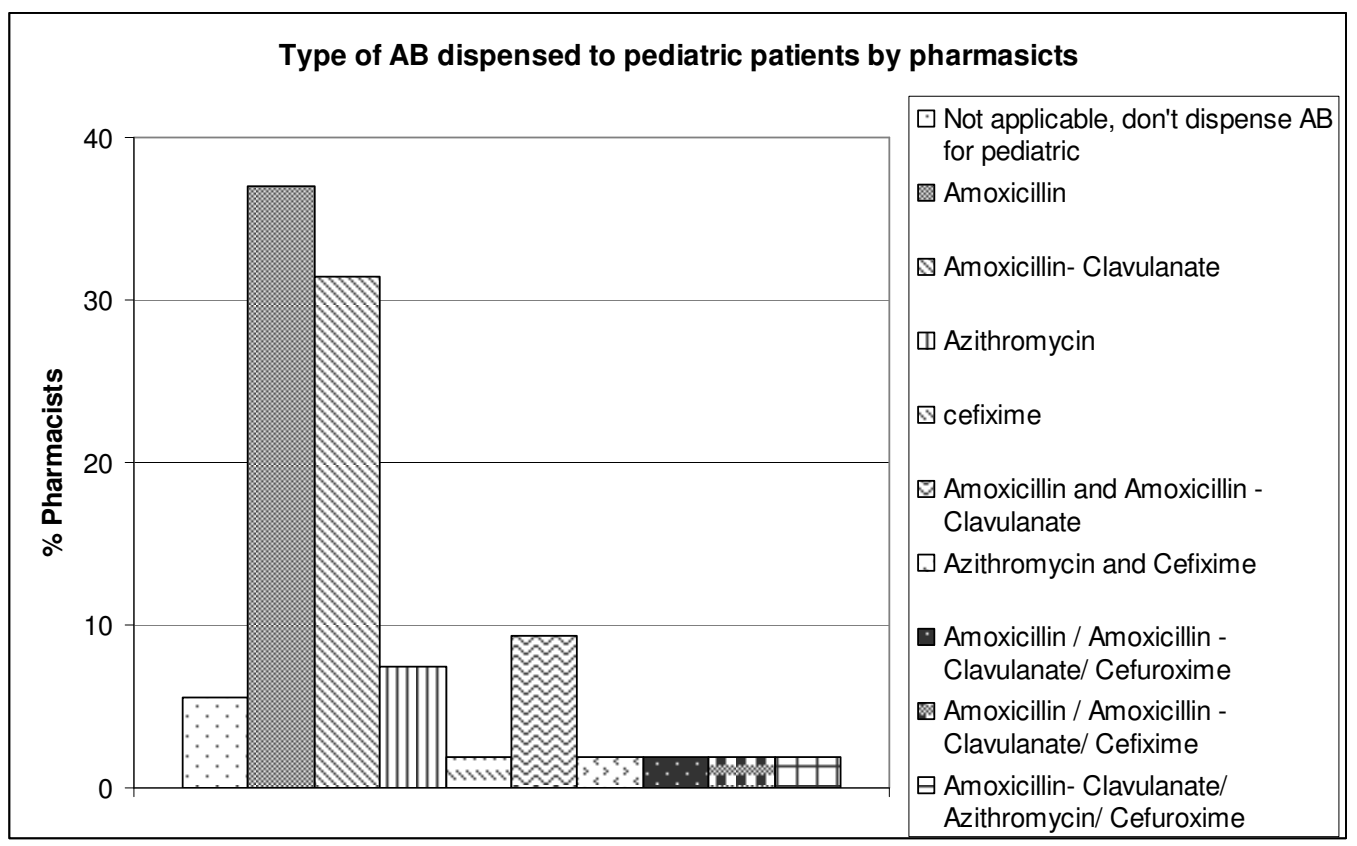

Fig. 2: Figure illustrates the types of $A B s$ dispensed to pediatric patients without prescription. 
In adults patients, $83.7 \%$ of $\mathrm{ABs}$ dispensed contained either amoxicillin or amoxicillin/Clavulanic acid product as first choice. The second choice was cefuroxime with $7.4 \%$ and the third choice was for azithromycin with around $5.6 \%$ of antibiotics dispensed without prescriptions (Fig. 3).

The cost of $\mathrm{ABs}$ dispensed without prescription varied, $33.3 \%$ of the pharmacists estimated their daily sales of $\mathrm{AB}$ sold without prescription between 1-10 Jordanian Dinar (JD) per day (one JD is equivalent to about 0.9 Sterling pound or about 1.4 US dollars), while $29.6 \%$ of pharmacists estimated this value to range from 10 to $20 \mathrm{JD}$ per day. $31.5 \%$ of pharmacists stated that they dispense $A B$ without prescription with a value of more than 30 JD per day (Fig. 4).

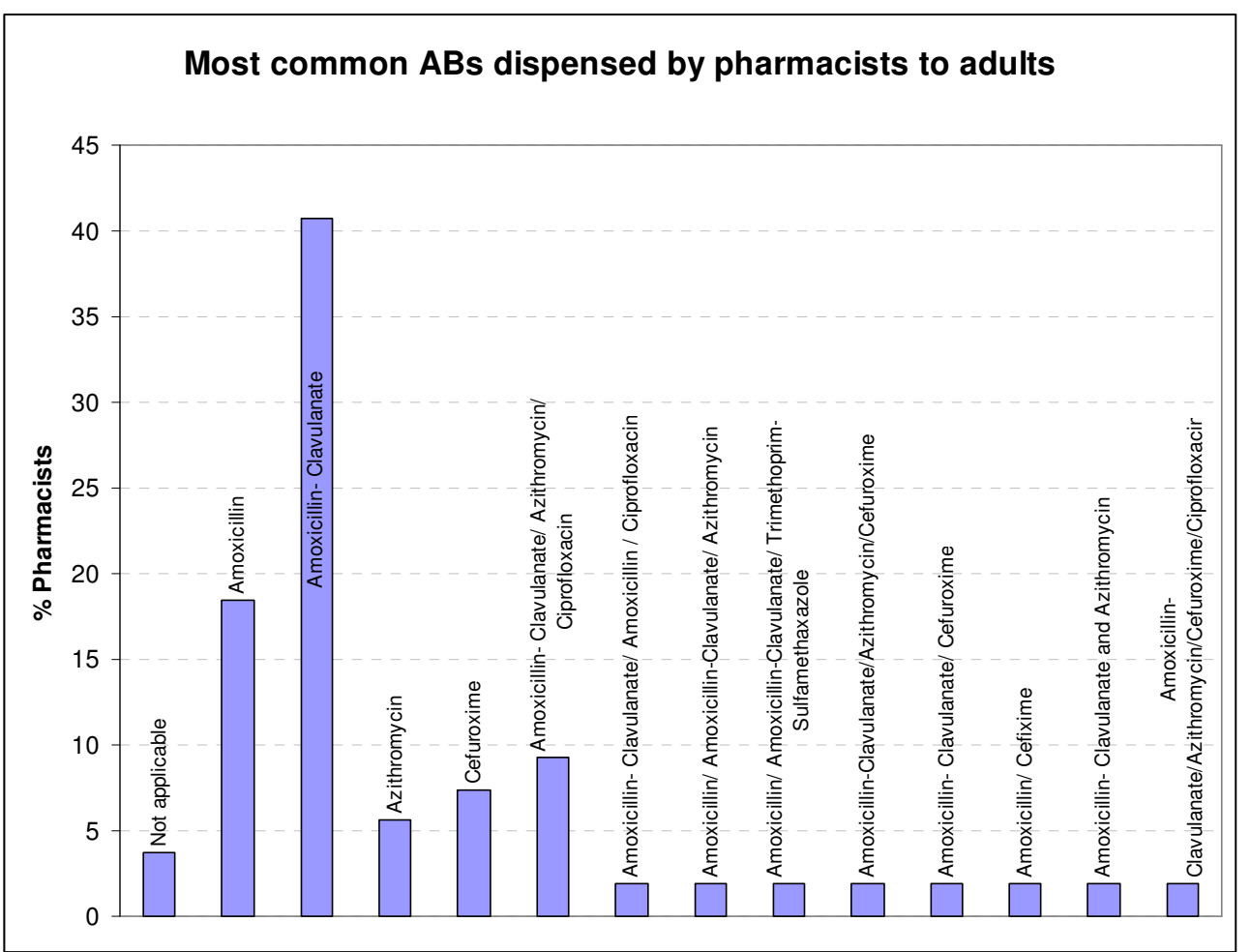

Fig. 3: Figure illustrates the most common ABs dispensed by pharmacists without prescription.

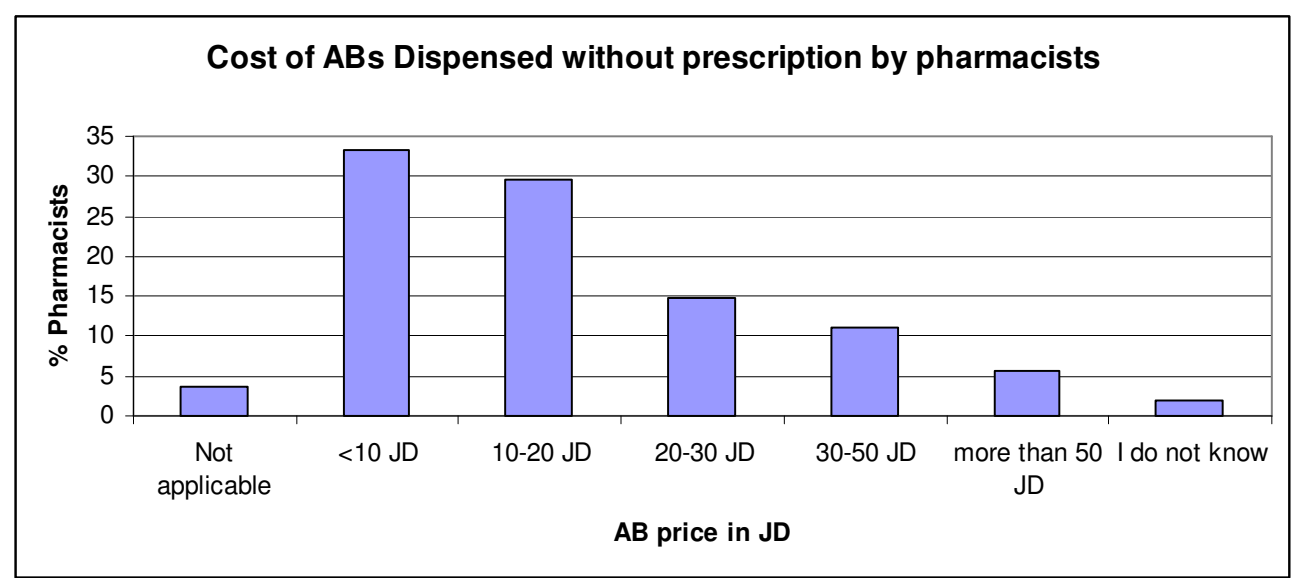

Fig. 4: Figure illustrates the cost of different $A B s$ dispensed without prescription by pharmacists daily. Values are represented in JD which indicates Jordanian Dinar (equivalent to around \$1.4 USD). 
Sore throat (tonsillitis) came as the foremost indication for $\mathrm{ABs}$ dispensed without prescription with $38.9 \%$; flu came second at $16.7 \%$. Less frequent indications like common cold and UTI were at $7.4 \%$ and $3.7 \%$, respectively (Fig. 5).

$43.4 \%$ of the interviewed pharmacists believed that patients skipped physicians' visits in order to avoid visit cost. $17 \%$ of pharmacists believed that the reasons for dispensing $\mathrm{ABs}$ without prescriptions are accessibility of pharmacies compared to physicians. Other less common causes are related to social perceptions and beliefs about pharmacists (1.9\% for both causes, Fig. 6).

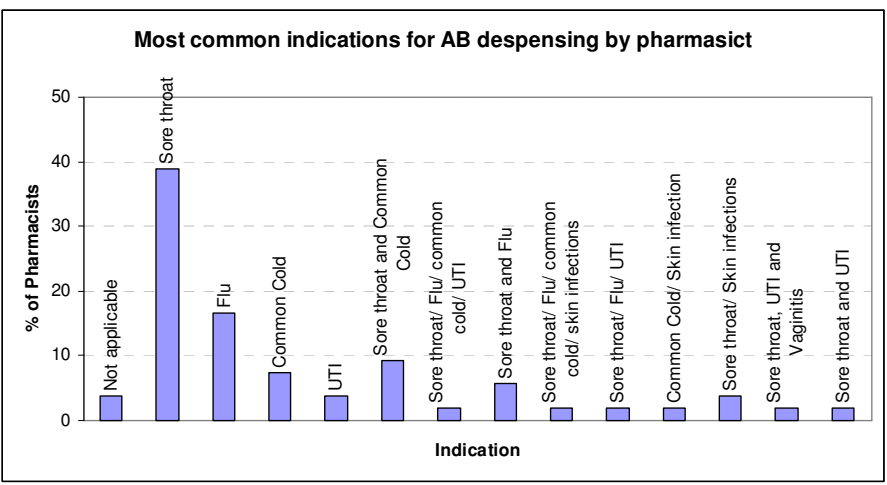

Fig. 5: Figure illustrates the most common indications that pharmacists dispense $A B s$ for without relying on prescription. UTI: Urinary tract infection.

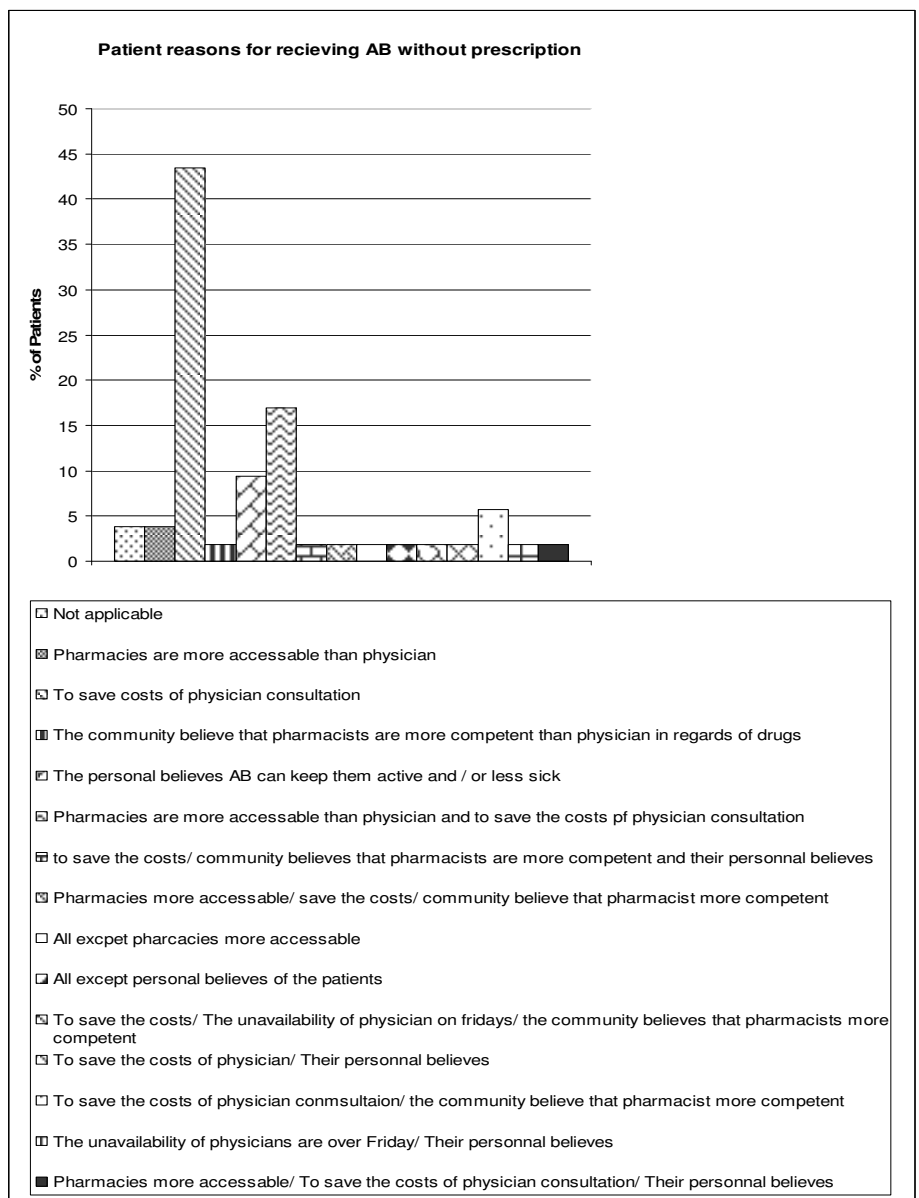

Fig. 6: Figure illustrates what pharmacists saw as reasons for patients receiving of $A B$ without prescription. 
$18.5 \%$ of interviewed pharmacists believed that the only reason for dispensing ABs without a prescription was to avoid physicians' visit. $22.2 \%$ of the interviewed pharmacists believed they have knowledge required to dispense $\mathrm{ABs}$ without a prescription and their patients cannot afford going to physician. While $12.7 \%$ answered that they believe they have necessary knowledge regardless of the physician's fees (Fig. 7).

The results of evaluating proper patient counseling upon $\mathrm{AB}$ dispensing were found to be reasonable in certain areas. $92.5 \%$ of pharmacists inquired about pregnancy in female patients, $81.1 \%$ of pharmacists questioned patients about receiving other $\mathrm{ABs}$ for the same infection and $94.2 \%$ of pharmacists asked their patients about signs and the symptoms before dispensing the $\mathrm{AB}$. However, only $38.5 \%$ of pharmacists asked patients if they have liver disease, $46.2 \%$ asked about renal problems, and just $23.1 \%$ of the interviewed pharmacists asked their patients if they have had a confirmed diagnosis (Fig. 8).
As for the $57.4 \%$ pharmacists who agreed that dispensing of $\mathrm{ABs}$ without a prescription was a problem in Jordan (Fig. 8), the most common suggested solutions were, to stop dispensing $\mathrm{ABs}$ without prescription by pharmacists (16.7\%), instating education programs directed to the community (11.1\%), enforcing already existed regulations about dispensing medications without prescriptions by the ministry of health $(9.3 \%)$, and $5.6 \%$ of them suggested regulations enforcement in addition to providing educational programs (Fig. 9).

The remaining $14.7 \%$ of pharmacists participated in the questionnaire believed that to solve this problem more than one action need to be taken included the previous suggested solutions along with other solutions like pharmacy association enforce new regulations and providing a good healthcare insurance by the government to the whole community (Fig. 9).

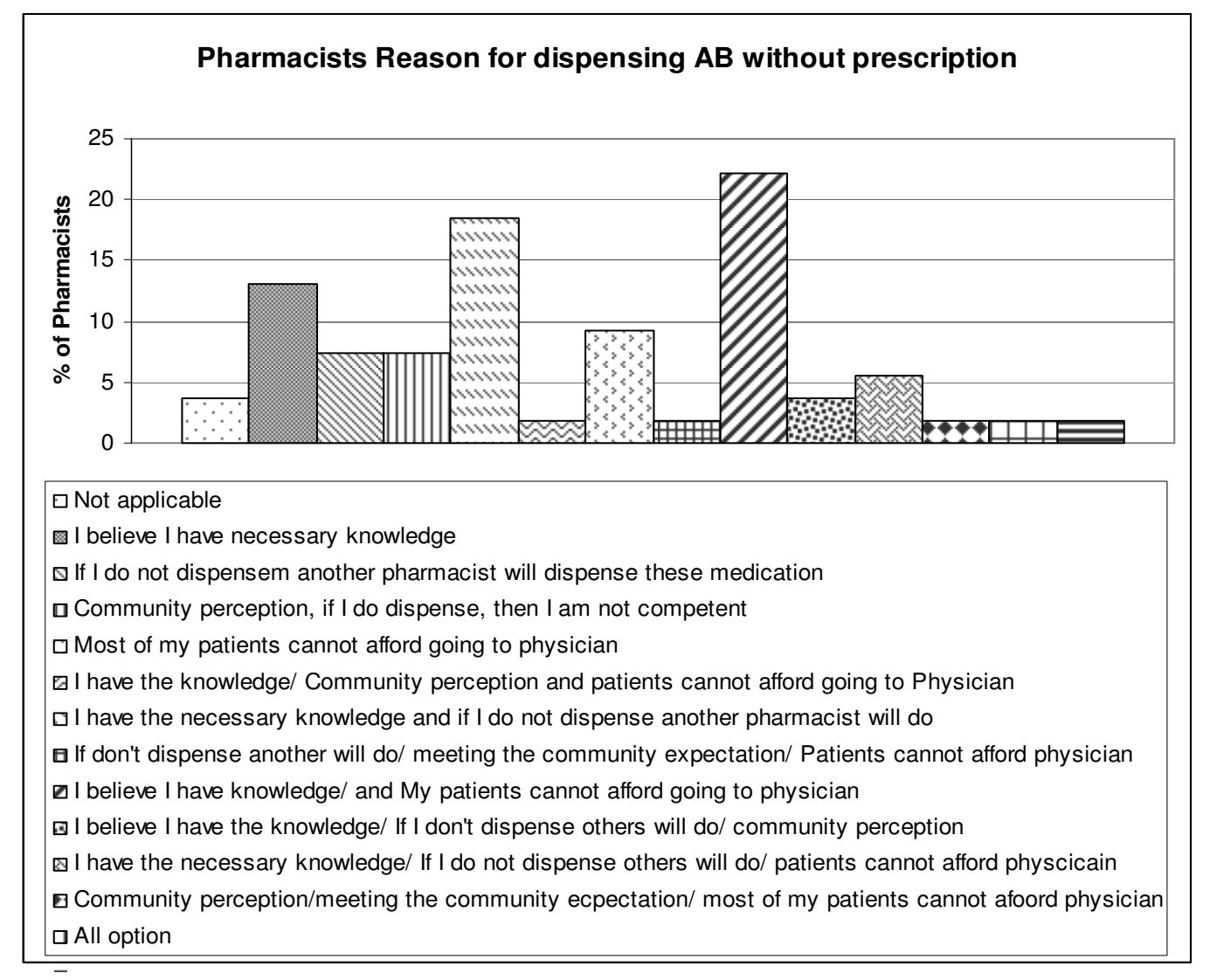

Fig. 7: Figure illustrates the reasons behind their dispensing ABs without proper medical prescription. 


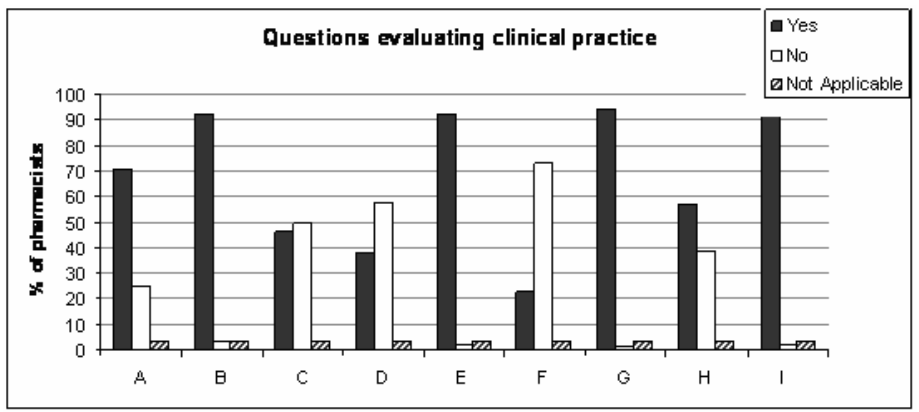
A Do you ask about if patient is diagnosis with other disease?
B Do you ask if the patient recently received other medication to treat the same complaint?
C Do you ask the patient about Kidney Problems?
D Do you ask Patients about liver disease?
E Do you ask about signs and symptoms before dispensing $\mathrm{AB}$ ?
F Do you ask about blood tests that confirm infection before dispensing $\mathrm{AB}$ ?
G Do you ask patients about allergies?
H Do you think that dispensing AB without prescription is problem in Jordan?
I Do you ask female patients if they are pregnant or not?

Fig. 8: Figure illustrates important questions asked to evaluate pharmacist's behavior in terms of following some correct clinical practice guidelines. The following questions were asked and the answer was either yes, no or not applicable.

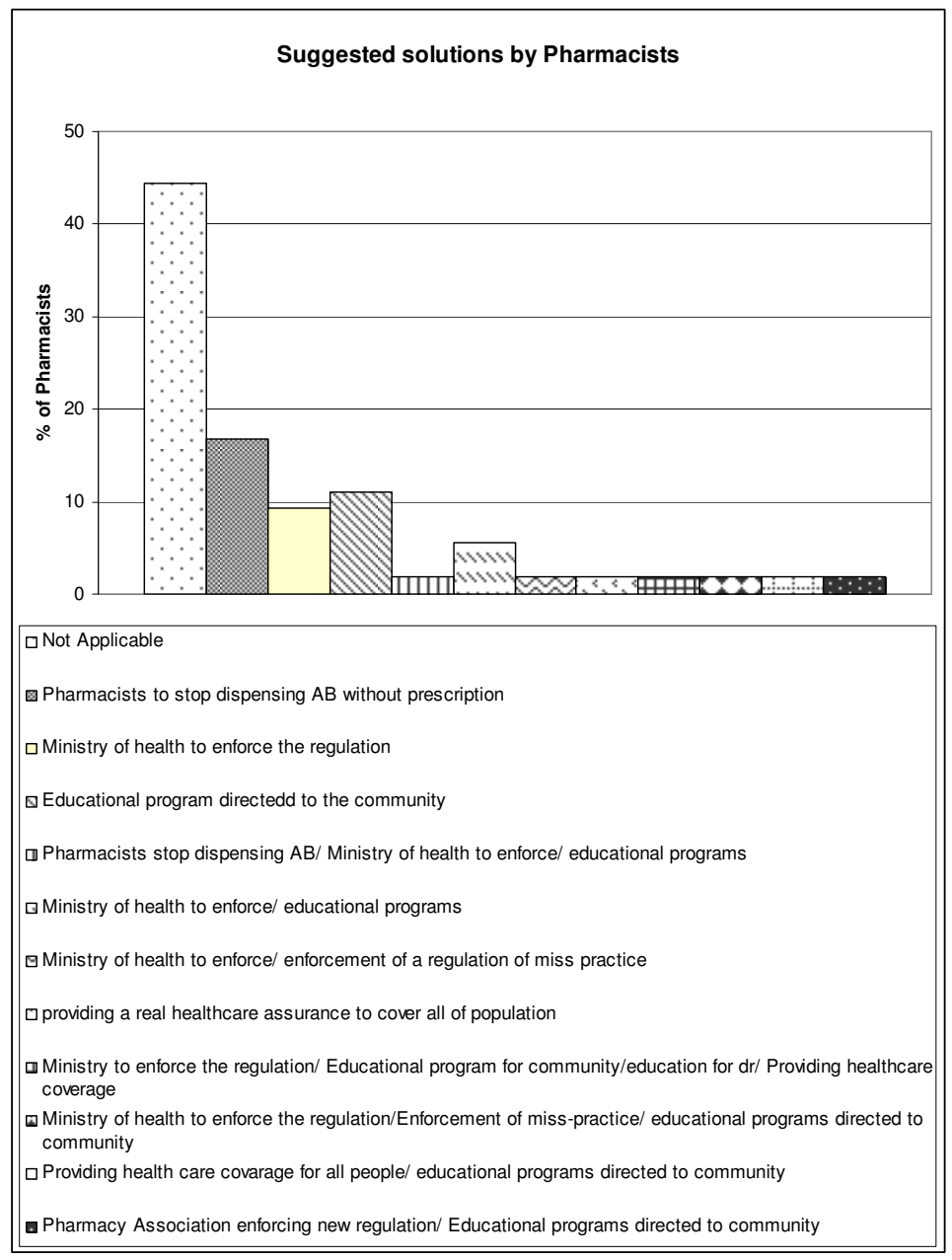

Fig. 9: Figure illustrates solutions that pharmacist suggested to control dispensing ABs without prescription. 


\section{Discussion}

The results obtained in this study indicate that the most commonly dispensed $\mathrm{ABs}$ without prescription by community pharmacists were amoxicillin and amoxicillin containing drugs. This was apparent for medications intended for both adults and pediatrics where more than $80 \%$ of $\mathrm{ABs}$ were of this type. These results were consistent with a previous study conducted at King Hussein Medical center outpatient's pharmacies which is part of the royal medical services (RMS) in Jordan, which looked into the antibiotic prescriptions distribution, where amoxicillin combinations were at the top of $\mathrm{ABs}$ prescribed ${ }^{13}$. Also, in the United Arab Emirates, Amoxicillin was the most commonly used $\mathrm{AB}$ by self medication where more than $46 \%$ of the examined sample stated the use of this medication ${ }^{7}$. In their study, Abasaeed and co-workers attributed their observations to the multinational composition of the UAE population where it consisted mainly of Pakistani, Philipino, Indian and other Arab country nationals, and that selfmedication with $\mathrm{ABs}$ was a common practice at the home countries of these different nationals. The previous study also found that selfmedication with $\mathrm{ABs}$ was common due to the ease of obtaining $\mathrm{ABs}$ at community pharmacies without prescription ${ }^{7}$. In Jordan, the wide use of amoxicillin can be attributed to the low cost of such medication with broad indication profile where the effectiveness of amoxicillin as an antibiotic has been established in controlling infections of the upper and lower respiratory tract, ear infections, urinary tract infections, gastrointestinal infections and many more. Here, a 5 day course of amoxicillin would cost around 3 JOD. Amoxicillin- Clavulanic acid cost is around $10 \mathrm{JOD}$. Other antibiotics may considerably cost more.

The most common use of non prescription ABs was to treat sore throat or tonsillitis. This was consistent with the finding of both Grigoryan and co-workers, and Mohanna ${ }^{6 \& 12}$. Here, both researches reported that $80 \%$ of causes for self-medication in children were to treat respiratory symptoms.

Also, in a previous survey conducted by Yousef and co-workers, $37.3 \%$ of the patients stated that the reason for self-medication was the long waiting times at physician's offices.
This was mostly apparent in public health services but not in private clinics. A significant number of patients also admitted that they avoided the doctor's clinic to save on visit $\operatorname{costs}^{10}$. In this study, it was revealed that the number one reason for self-medication with $\mathrm{ABs}$ was to avoid the physician's fees.

The results in the current study were expressed from the pharmacists point of view, and patients were believed to seek ABs without a prescription because they found community pharmacies to be more accessable than physicians. This is certainly apparent in the middle income population living in eastern amman, where they find it easier to communicate with the pharmacist than with the phyisician. Here, the physicians visit involves waiting in a reception area for a period of time untill actually seeing the physician, this waiting period is sometimes long. In addition, some patients may be intemedated by the whole clinic setting and may find it less comfortable to express themselves in the presence of the physician. On the other hand, the nature of the pharmacy setting in Jordan, where the pharmacist is considered to be of similar social backround as the people living in an area and the fact that it is very easy to just walk into the pharmacy and ask for advice may significantly effect the communication where patients find themselves at ease discussing any malady or symptom. Patients will also feel they have more time to communicate with the pharmacist as there is no waiting room and minimal waiting time. The presence of such a difference in the environment leading to the face to face communication between patients and health care providers may itself influence the patients perception on the quality of medical service provided. Add that to the saved cost of phisician visit, where a significant number of pharmacists expressed they believed that patients resorted to the pharmacist first to save the costs of physician consultation, it is not unreasonable that at times the pharmacist may be considered by the patient a more superior overall health care provider than the physician. Also, Just over a fifth of the pharmacists believed that they were entitled to dispense $\mathrm{ABs}$ because they thought they possessed the necessary knowledge and that their patients couldn't afford going to doctor's clinic. $18.5 \%$ of the pharmacists stated that the only reason 
for dispensing $\mathrm{ABs}$ was their beliefs that patients cannot afford going to see a physician. So in this situation they would actually be helping the patient in saving cost. This is truly unfortunate when pharmacists should help the patient through referring them to the physician for proper consult, while in this study it was revealed that pharmacists behaved in a opposed manner when they actually encouraged avoiding physicians by easily providing patients with a complete health service from diagnosis to treatment. Also, when $12.7 \%$ of the studied pharmacist population dispensed ABs simply because they believed they possessed the necessary knowledge and skills to do so, a fundamental flaw became apparent, where pharmacists failed to distinguish between the different duties of each discipline in the health care profession.

Consequences of dispensing $\mathrm{ABs}$ without prescription can also be apparent in our finding when the majority of pharmacists showed a commitment for asking female patients about pregnancy, signs and symptoms, and previous $\mathrm{ABs}$ treatment before they dispense ABs without prescription. Less than half of the surveyed pharmacists asked the patients about liver disease or any kidney insufficiencies. This creates a problem since many medications will require dosage adjustment in the presence of such defficiencies, and consequently might put some patients under the risk of exceeding the therapeutic index and encounter toxic drug effects.

Dispensing of antibiotics without a prescription is a threat which varies by city, region, and country. The continued practice of such behavior will more likely lead to the emergence of newer antibiotic resistant bacteria. This practice will also expose patients to unnecessary side-effects that are related to irrational use of the medication. According to a study conducted in Mexico, antibiotic resistance is an exacerbating problem in developing countries in comparison to the US or Europe. Here, this was attributed to the unrestricted access of medication in the developing countries, and the financial burden that patients need to endure to see a physician ${ }^{2}$. These same reasons are relevant to Jordan, as there is still no restriction to medication access in the pharmacy. This problem might be apparent in Jordan where the uncontrolled use of ABs among the population (46\% of the population) may result in an antibiotic resistance endemic ${ }^{9}$.

And although the majority of medications available in community pharmacies are dispensed without restriction, there are very tough restrictions on some medications such as drugs with abuse potential, where it is almost impossible to acquire a schedule drug from the pharmacy without prescription. The latter proves that the Jordanian health care services possess the ability to implement restrictions on medication dispensing. And for AB dispensing to receive similar regulations and restrictions as drugs with abuse potential, proper education should be provided to policy makers in order overcome this problem and its negative impact on the society. This education should also reach the community pharmacists where $42.6 \%$ of the interviewed pharmacists believed that dispensing $\mathrm{ABs}$ without prescription in Jordan was not considered as a problem and only $16.7 \%$ of the researched group admitted the presence of a problem and that pharmacists should stop dispensing ABs without prescription to solve this issue.

When prescribing $\mathrm{ABs}$ without prescription was considered to be a problem, only $11.1 \%$ of pharmacists believed that extra education to the community will help to stop self-medication, and when education was considered necessary, pharmacists deemed that it should be directed to the community and not the pharmacist, which worsens the problem. Here, the pharmacists believed that dispensing $\mathrm{ABs}$ without prescription was the patient's fault because they sought the medication without having a physician's prescription. In reality, if pharmacists refused dispensing medications without prescription, patients would have no alternative but to seek proper medical diagnosis through visiting the physician. In fact, contrary to pharmacist belief, it is recommended that pharmacists be educated on the consequences of dispensing $\mathrm{ABs}$ without prescription. This education should be carried out by the ministry of health where $9.3 \%$ of pharmacist believed that it is the responsibility of ministry of health to enforce regulations to prevent $\mathrm{AB}$ dispensing without prescription. It is recommended that these regulations be communicated to the pharmacist through proper educational sessions in collaboration 
with the Jordanian Pharmacist Association (JPA). This education is expected to be well received as $62.9 \%$ of pharmacists in this study believed that to solve this issue a multidisciplinary approach would be required where the community, pharmacy association, ministry of health and pharmacists cooperate to stop or at least reduce $\mathrm{AB}$ self-medication among the population.

\section{Appendix}

Survey of pharmacist opinions in regards of dispensing of $A B$ without prescription

Part I. Please check the box(es) that most appropriately answers the questions.

Q1. How often do you dispense antibiotic without medical prescription per day, based on your estimation?

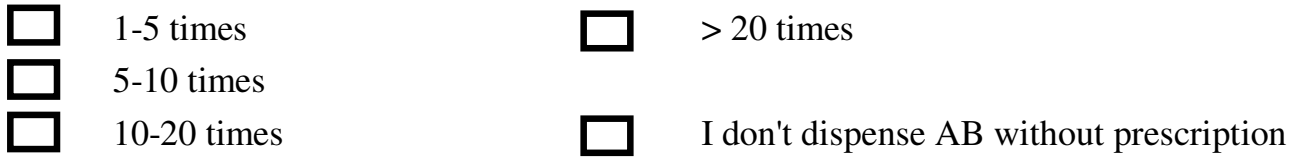

Q2. Based on your experience, which is the most prescribed AB without prescription for:

\section{A. Pediatric patients?}

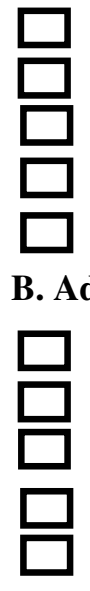

Amoxicillin

Amoxicillin - Clavulanate

Trimethoprim- Sulfamethaxazole

Azithromycin

Macrolides $\square$ Penicillin

Amoxicillin

Amoxicillin - Clavulanate

Trimethoprim- Sulfamethaxazole

Azithromycin

Macrolides $\square$ Penicillin

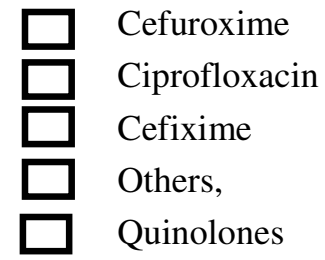

Cephalosporin

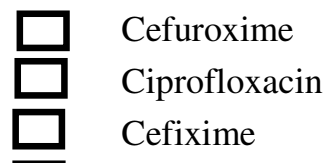

$\square$ others,

Quinolones

Q3. Based on your experience, what is your estimation of the total costs of the AB medication you dispense without prescription per day (on average)?

1-10 JD

10-20 JD

20-30 JD $\square \quad 30-50 \mathrm{JD}$

$\square>50 \mathrm{JD}$

$\square$ I do not know

Q4. Based on your experience, which is the most common indication for using AB without prescription among the community?

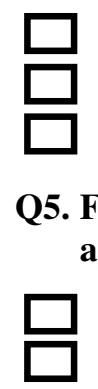

Sore throat

Flu

Common Cold applicable)

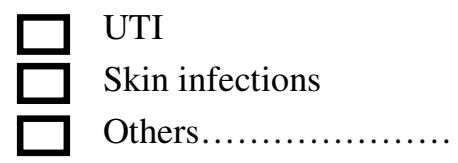

Q5. From your point of view, why do you dispense AB without prescription? (Check all

I believe I have the necessary knowledge

If I do not dispense, another pharmacist will dispense these medication 
Community perception, if I do not dispense, then I am not competent

Meeting the community expectation, that pharmacist knows

Make a profit

Most of my patients cannot afford going to physician

Q6. From your point of view, why do you think patients seek AB without prescription? (Check all applicable)

Pharmacies are more accessable than physician

To save the costs of physician consultation

The unavailability of physicains on Fridays

The community believe that pharmacist more competent than physician in regards of drugs

Their personnal believes (AB can keep them active or and less sick )

\section{Q7. Do you think that dispensiong AB without perscription is a problem in Jordan ?}

$\square$ Yes $\square$ No

If you answered Yes for question number seven, how can this issue be solved from your point of view?

Pharmacists to stop dispensing $\mathrm{AB}$ without prescription

Ministry of health to enforcing the regulation

Pharmacy association enforcing new regulation

Enforcement of a regulation of mis practice

Educational programs directed to the community

Others,

Part II. Please check the box that is applicable,

Before you dispense the $\mathrm{AB}$ do you ask the patient the following questions?

\begin{tabular}{|lll|}
\hline $\mathbf{1}$ & Do you ask if the patient has any allergies \\
\hline $\mathbf{2}$ & Do you ask if the patient has any kidney problems \\
$\mathbf{3}$ & Do you ask if the patient has any liver problems \\
$\mathbf{4}$ & Do you ask the female patient if they are pregnant or not \\
$\mathbf{5}$ & $\begin{array}{l}\text { Do you ask the patient if he/she has been recently receive any } \\
\text { other medications for the same complaint }\end{array}$ \\
$\mathbf{6}$ & $\begin{array}{l}\text { Do you ask the patient if he/she has been diagnosed with any } \\
\text { disease }\end{array}$ \\
\hline $\mathbf{7}$ & $\begin{array}{l}\text { Do you ask the patient if he/she had any blood tests, to confirm } \\
\text { infection }\end{array}$ \\
\hline $\mathbf{8}$ & Do you ask the patient about signs and symptoms
\end{tabular}




\section{Conclusion}

The community pharmacists and the Jordanian Pharmacist Association and Ministry of Health need to work together to control the $\mathrm{AB}$ use among the Jordanian population. Enforcement of laws to control this practice, increasing awareness among patients and pharmacists, and empowering pharmacists to play more active role in patients care are important steps to be followed by the previously mentioned parties to control this practice.

Also, further studies are still required in order to compare eastern and western Amman communities in terms of their behavior regarding dispensing $\mathrm{ABs}$ without prescription. This will give us more insight into this practice especially when there is significant socioeconomic variation between these different communities.

\section{REFERENCE}

1- WHO and FIP, "The Role of the Pharmacist in Self-Care and SelfMedication", (1998) Retrieved 26/4, 2012, http://apps.who.int/medicinedocs/en/d/Jw hozip32e./

2- C. Amabile-cuevas, "Antibiotic resistance in Mexico: a brief overview of the current status and its causes", J. Infect. Dev. Ctries., 4 (3), 126-131 (2010).

3- M. P. Goldman and R. Nair, "Antibacterial treatment strategies in hospitalized patients: what role for pharmacoeconomics?", Cleve. Clin. J. Med., 74, S38-4 (2007).

4- E. Skliros, P. Merkouris, A. Papazafiropoulou, A. Gikas, G. Matzouranis, C. Papafragos, I. Tsakanikas, I. Zarbala, A. Vasibosis, P. Stamataki and A. Sotiropoulos, "Self-medication with antibiotics in rural population in Greece: a cross-sectional multicenter study", BMC., 11 (2010).

5- F. Wong, F. Chan, J. You, E. Wong and E. Yeoh, "Patient self-management and pharmacist-led patient self-management in Hong Kong: A focus group study from different healthcare professionals perspectives", BMC Health Services Research, 11, 121 (2011).
6- L. Grigoryan, J. Burgerhof, J. Degener, R. Deschepper, C. Lundborg, D. Monnet, E. Scicluna, J. Birkin and F. Haaijerruskamp, "Determinants of selfmedication with antibiotics in Europe: the impact of beliefs, country wealth and the healthcare system", J. Antimicrob. Chemother., 61, 1172-9 (2008).

7- A. Abasaeed, J. Vlcek, M. Abuelkhair and A. Kubena, "Self-medication with antibiotics by the community of $\mathrm{Abu}$ Dhabi Emirate, United Arab Emirates", $\boldsymbol{J}$. Infect. Dev. Ctries., 3, 491-7, (2009)

8- N. Al- Momany, A. Al-Bakri, Z. Makahleh and M. Wazaify, "Adherence to international antimicrobial prophylaxis guidelines in cardiac surgery: a Jordanian study demonstrates need for quality improvement", J. Manag. Care. Pharm., 15, 262-71 (2009).

9- A. Al-Bakri, Y. Bustanji and A.Yousef, "Community consumption of antibacterial drugs within the Jordanian population: sources, patterns and appropriateness", Int. J. Antimicrob. Agents., 26, 389-95. (2005)

10- A. Yousef, A. Al-Bakri, Y. Bustanji and M. Wazaify, "Self-medication patterns in Amman, Jordan", Pharm. World, S30, 3024 (2008).

11- S. Otoom and R. Sequeira, "Health care providers' perceptions of the problems and causes of irrational use of drugs in two Middle East countries", Int. J. Clin. Pract., 60, 565-70 (2006).

12- M. Mohanna, "Self-medication with Antibiotic in Children in Sana'a City, Yemen", Oman, 25, 41-3 (2009).

13- S. Al-Niemat, D. Bloukh, M. Al-Harasis, A. Al-Fanek and R. Saleh, "Drug use evaluation of antibiotics prescribed in a Jordanian hospital outpatient and emergency clinics using WHO prescribing indicators", Saudi Med. J., 29, 743-8 (2008). 


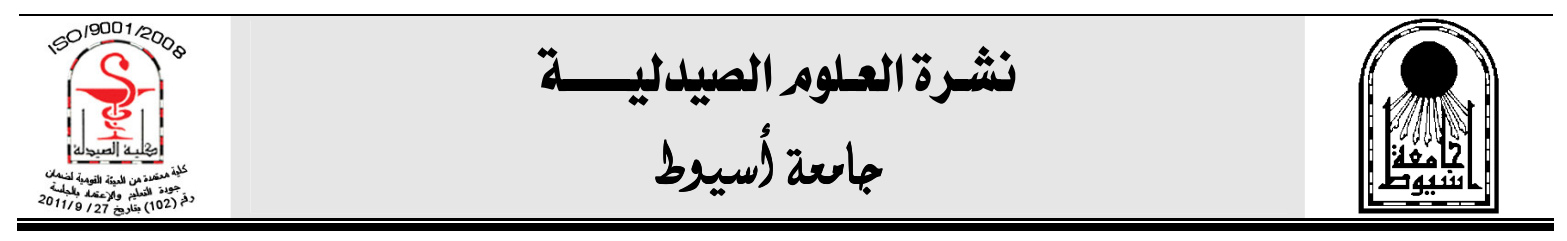

صرف المضادات الحيوية بدون وصفة طيية فى الصيدليات الأردنية:

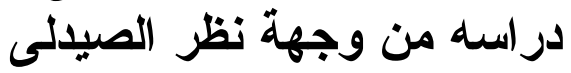

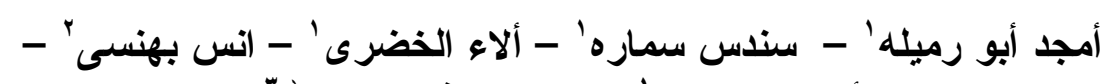

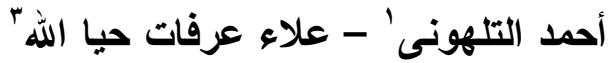

' قسم الكيمياء الصيدلية الاكلينيكية وقسم العلوم الصيدلانية التطبيقية ، كلية الصيدله ،

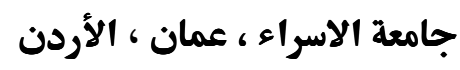

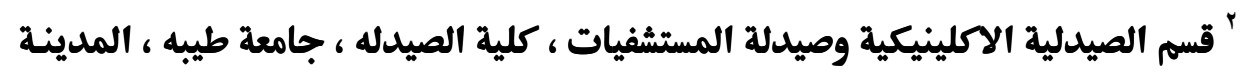

المنورة ، المملكة العربية السعودية

" قسم الكيمياء العضوية الصيدلية ، كلية الصيدله ، جامعة أسيوط ، مصر ،

لقد أصبح بيع المضادات الحيوية من غير وصفة طبية معروفا كمصدر رئيس مسن مــــادر

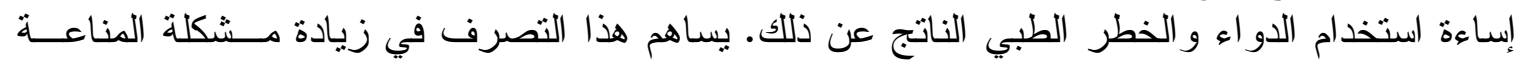

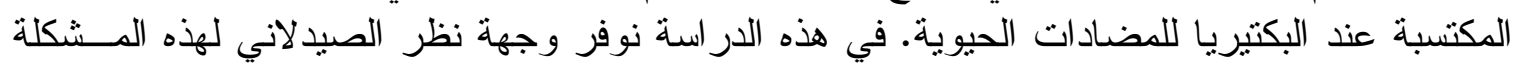

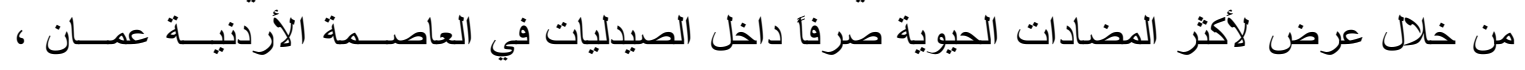

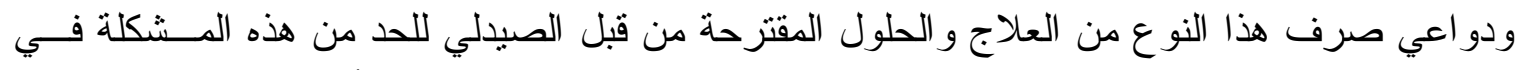

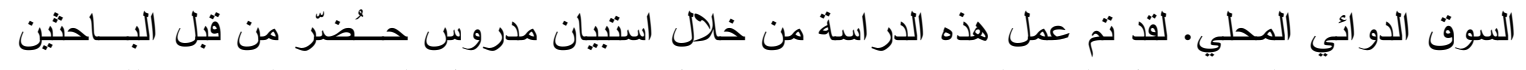

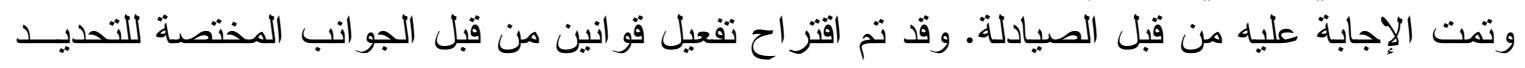

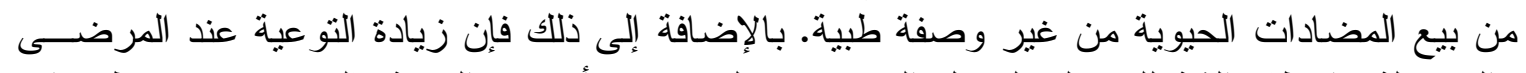

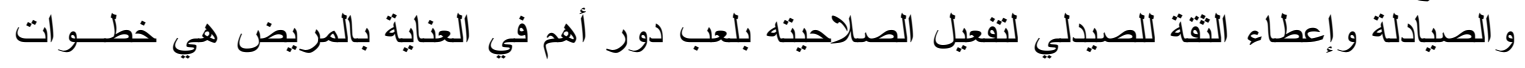
مهمة تناهم في التقليل من هذه المشكلة. 